\title{
Appendix A: Semi-Structured Interview Questions
}

Please describe your position.

Please describe the origins of your position. How has your position changed over time?

Please describe how your position is funded.

Please describe the population with which you work.

Do you collaborate or co-facilitate with any other professionals or staff members? With whom do you collaborate/co-facilitate? When and Why? What does that look like?

What are the goals of the music therapy (MT) sessions you lead?

What interventions do you use and how do they relate to specific goals?

How do you and your facility evaluate the effectiveness of MT interventions as working towards overall families' outcomes?

How does MT contribute to the overall continuum of desired outcomes of the organization for whom you work?

How do you perceive MT to help the families you work with? Why might the families like it?

How do the staff perceive MT?

What are potential barriers that prevent more MT in this facility?

How has the lack of MT literature about this population effected your position?

What MT research might be important to conduct with this population?

How could music therapy services be improved in your facility? 